\title{
PILIHAN PENGENDALIAN PENGGUNAAN MOBIL PRIBADI DENGAN STRATEGI PARKIR, ERP DAN TRANSJAKARTA DI JALAN RAYA SERPONG
}

\author{
Albert Fernando ${ }^{1}$ dan Najid ${ }^{2}$ \\ ${ }^{1}$ Program Studi Sarjana Teknik Sipil, Universitas Tarumanagara, Jl. Letjen S. Parman No.1 Jakarta \\ Email: albertfernandojr@gmail.com \\ ${ }^{2}$ Program Studi Sarjana Teknik Sipil, Universitas Tarumanagara, Jl. Letjen S. Parman No.1 Jakarta \\ Email: najid@ft.untar.ac.id
}

\begin{abstract}
ABSTRAK
Pengendalian penggunaan mobil pribadi menggunakan strategi Electronic Road Pricing, kebijakan parkir dan Transjakarta dapat mengurangi kepadatan lalu lintas. Tujuan dilakukannya penelitian ini adalah untuk menganalisis respon masyarakat terhadap sistem Electronic Road Pricing, kebijakan parkir dan Transjakarta jika diterapkan untuk mengurangi kepadatan lalu lintas. Electronic Road Pricing telah berhasil menanggulangi kemacetan di beberapa negara dengan memberikan tarif berbayar pada jalan tertentu. Sistem kebijakan parkir dapat mengurangi kepadatan lalu lintas dengan menaikan tarif parkir sesuai dengan kepadatan penggunaan kendaraan pribadi di daerah tertentu. Tujuan dari sistem Electronic Road Pricing dan kebijakan parkir agar pengguna kendaraan pribadi beralih menggunakan kendaraan umum untuk mengurangi kepadatan lalu lintas. Pengambilan data untuk penelitian ini diambil dengan cara penyebaran kuesioner di Jalan Raya Serpong kepada responden yang mengetahui dan pernah melewati jalan tersebut. Data yang didapat dari responden, akan diolah agar dapat mengetahui pilihan dari responden tentang kedua sistem tersebut dengan menggunakan model analisis sensitivitas. Strategi parkir, ERP dan Transjakarta dianggap menjadi salah satu solusi untuk mengurangi kepadatan lalu lintas. Hasil dari penelitian ini adalah ketika strategi ERP dan kebijakan parkir diterapkan dengan tarif yang tinggi maka pengguna Jalan Raya Serpong akan beralih menggunakan kendaraan umum dan didapatkan bahwa responden cenderung lebih memilih tarif yang lebih murah.
\end{abstract}

Kata kunci: Electronic Road Pricing, Kebijakan Parkir, Pengendalian Mobil Pribadi, Jalan Raya Serpong, Transjakarta

\section{PENDAHULUAN}

Transportasi digunakan untuk memudahkan manusia dalam melakukan aktivitas sehari-hari karena dapat mengefisienkan waktu khususnya pada transportasi darat. Transportasi adalah perpindahan manusia atau barang dari satu tempat ke tempat lainnya dengan menggunakan sebuah kendaraan yang digerakkan oleh manusia atau mesin. Di negara berkembang seperti Indonesia, permasalahan transportasi darat khususnya kepadatan lalu lintas sudah berlangsung lama terutama di kota - kota besar seperti di Provinsi Banten. Hingga tahun 2015 lalu tercatat pada data Badan Pusat Statistik (BPS) Provinsi Banten bahwa jumlah penduduk adalah 11.955.243 jiwa. Berdasarkan data yang didapat, daerah kabupaten Tangerang merupakan daerah terpadat di Provinsi Banten. Kota yang berpenduduk lebih dari 2-3 juta jiwa dapat dipastikan mempunyai permasalahan transportasi (Tamin, 2008). Salah satu solusi yang rencananya akan diterapkan untuk upaya permasalahan transportasi darah yang terjadi adalah dengan menerapkan sistem Electronic Road Pricing (ERP) atau dengan solusi pengendalian parkir di kabupaten Tangerang. Hal ini dikarenakan apabila daerah DKI Jakarta telah menerapkan kebijakan sistem Electronic Road Pricing (ERP) atau pengendalian parkir, maka kota - kota besar seperti di Provinsi Banten yang memiliki kepadatan lalu lintas tinggi akan menggunakan kebijakan yang sama juga.

\section{Tujuan penelitian}

Tujuan penelitian ini adalah untuk mengetahui perbandingan antara sistem Electronic Road Pricing dan Kebijakan Parkir, serta membandingkan kedua sistem tersebut terhadap rata - rata pendapatan penghasilan dan pengguna kendaraan pribadi mobil, membandingkan penggunaan kendaraan pribadi dengan kebijakan Electronic Road Pricing (ERP) terhadap kendaraan umum Transjakarta dan membandingkan penggunaan kendaraan pribadi dengan kebijakan parkir terhadap kendaraan umum Transjakarta dan taxi online. 


\section{Electronic Road Pricing (ERP)}

Eletronic Road Pricing adalah salah satu strategi dalam kebijakan sistem transportasi yang berkelanjutan (sustainable transport sistem policy). Secara umum ERP adalah manajemen permintaan perjalanan (Travel Demand Management) yang bertujuan untuk mendorong pengguna jalan untuk mengurangi perjalanan yang relatif tidak perlu dan mendorong penggunaan moda transportasi yang lebih efektif, lebih sehat, dan ramah lingkungan. Kebijakan Travel Demand Management dapat dikelompokan menjadi tiga grup yaitu: instrument - instrument regulasi (regulatory instruments), persetujuan - persetujuan kerjasama (cooperative agreements), dan instrument instrument ekonomi (economic instruments). (Susantono, 2010). Congestion pricing (pungutan biaya kemacetan) merupakan salah satu economic instrument yang bertujuan untuk mengurangi penggunaan kendaraan pribadi. Electronic Road Pricing (ERP) adalah kebijakan pemberlakuan jalan berbayar untuk setiap kendaran pribadi yang melewatinya. ERP bertujuan mengurangi kemacetan di ruas jalan tertentu pada jam - jam tertentu, biasanya pada jam - jam padat atau peak hour, sehingga dapat mengurangi kemacetan pada daerah tersebut yang juga berdampak kepada daerah lainnya. Tujuan penerapan ERP adalah agar arus kendaraan menjadi lebih lancar. Sistem ini mampu secara otomatis berfungsi seperti gerbang tol tanpa harus mengurangi atau memberhentikan kecepatan kendaraan yang akan memasuki daerah ERP seperti yang terjadi di jalan tol. (Goh, 2002)

\section{Rencana penerapan Electronic Road Pricing (ERP) di Indonesia}

Sistem Electronic Road Pricing (ERP) merupakan sistem pungutan kemacetan menggunakan kartu elektronik. Sistem ini membebankan sejumlah biaya kepada pemilik kendaraan karena akan melewati suatu jalur tertentu sebab kendaraannya berpotensi menyebabkan kemacetan pada waktu tertentu. Penggunaan sistem ini pernah dilontarkan oleh mantan Gubernur Sutiyoso pada November 2006, dan sekarang menjadi sebuah wacana yang akan diimplementasikan. Menurutnya, sistem ini sangat cocok untuk diberlakukan di Jakarta dan di kota - kota besar lainnya seperti Tangerang dan telah sejalan dengan kebijakan transportasi makro melalui peraturan daerah tentang pembatasan kawasan lalu lintas. melalui sistem ini, diharapkan dapat mengurangi pemakaian kendaraan pribadi, dan penduduk beralih menggunakan kendaraan umum. Jumlah kendaraan pribadi di Jakarta dan Tangerang mencapai 90\% pengguna jalan, sedangkan kendaraan umum hanya mengisi dua persen sisanya. Dengan kondisi ini, pembatasan kendaraan pribadi dapat terlaksana hanya jika bersamaan dengan ketersediaan sarana transportasi publik (kendaraan umum) yang memadai, baik jumlah maupun kualitasnya. Dengan diterapkannya kebijakan ERP di provinsi DKI Jakarta, kota - kota besar lainnya juga dapat menerapkannya juga guna untuk menurunkan kepadatan lalu lintas dan dapat mendorong masyarakat untuk menggunakan kendaraan umum.

\section{Pengendalian strategi ERP}

Salah satu strategi dalam mengatasi kemacetan dan menuju sistem transportasi yang berkelanjutan (sustainable transport system policy) adalah manajemen permintaan perjalanan Travel Demand Management adalah untuk mendorong pengguna jalan untuk mengurangi perjalanan yang relatif tidak perlu (terutama pengguna kendaraan pribadi) dan mendorong penggunaan moda transportasi yang lebih efektif, lebih sehat, dan ramah lingkungan. Kebijakan Travel Demand Management dapat dikelompokkan menjadi tiga grup yaitu: instrumen-instrumen ekonomi (economic instruments), persetujuan-persetujuan kerjasama (cooperative agreements), dan instrumeninstrumen regulasi (Susantono,2010).

\section{Keuntungan menggunakan strategi Electronic Road Pricing (ERP)}

1. Penghematan konsumsi BBM.

2. Penurunan polusi udara.

3. Kepadatan lalu lintas berkurang.

4. Perpindahan penggunaan kendaraan pribadi ke angkutan umum.

\section{Prasyaratan keberhasilan ERP}

Dukungan masyarakat akan sangat berpengaruh terhadap berhasil tidaknya aplikasi road pricing (ERP). Pemerintah harus melibatkan masyarakat dalam mengambil keputusan dan harus mampu menjelaskan tujuan dan maksud ERP secara mudah dan jelas, bagaimana ERP akan mengatasi masalah-masalah kemacetan dan masalah transportasi lain; keuntungan dan kerugian ERP untuk masyarakat; bagaimana masalah equity dan privacy akan dilindungi; antisipasi terhadap pihak-pihak atau bisnis yang akan terpengaruh, terutama karena perubahan tata guna lahan, bagaimana pendapatan dari ERP akan dikelola dan dipergunakan. 
ERP tidak akan berhasil apabila diterapkan secara parsial, tidak terintegrasi dengan strategi lain. ERP akan berhasil apabila merupakan salah satu bagian dari sebuah integrated transport policy. Beberapa teknik manajemen permintaan lalu lintas yang akan bersinergi baik dengan ERP seperti pajak bahan bakar, kontrol penggunaan dan pemilikan kendaraan, pengawasan land-use development dan Transit Oriented Development (TOD), Intelligent transport sistems (ITS), parking controls dan pricing, dll.

Sebelum ERP diaplikasikan, hendaknya telah dipersiapkan landasan hukumnya, serta perangkat technology dan sumber daya manusia yang akan berfungsi dalam penegakan aturan (law enforcement). Landasan hukum yang akan digunakan juga harus memuat tentang lembaga yang akan mengoperasikan aspek teknis ERP, mengelola keuangan, dan melakukan law enforcement. Lembaga yang efisien, transparan, dan akuntable sangat menunjang keberhasilan aplikasi ERP (Sugitimo,2008).

\section{Pengendalian parkir}

Pengendalian parkir dilakukan untuk mendorong penggunaan sumber daya parkir secara lebih efisien serta digunakan juga sebagai alat untuk membatasi arus kendaraan ke suatu kawasan yang perlu dibatasi lalu lintasnya. Pengendalian parkir merupakan alat manajemen kebutuhan lalu lintas yang biasa digunakan untuk mengendalikan kendaraan yang akan menuju suatu kawasan ataupun perkantoran tertentu sehingga dapat diharapkan akan terjadi peningkatan kinerja lalu lintas di kawasan tersebut. Pengendalian parkir harus diatur dalam Peraturan Daerah tentang parkir agar mempunyai kekuatan hukum dan diwujudkan rambu larangan, rambu petunjuk dan informasi. Untuk meningkatkan kepatuhan masyarakat terhadap kebijakan yang diterapkan dalam pengendalian parkir perlu diambil langkah yang tegas dalam menindak para pelanggar kebijakan parkir.

\section{Instrumen kebijakan parkir}

Beberapa kebijakan parkir yang diterapkan diberbagai negara antara lain (Abubakar,2011):

1. Kebijakan tarif parkir yang ditetapkan berdasarkan lokasi dan waktu, semakin dekat dengan pusat kegiatan/kota tarif lebih tinggi, demikian juga semakin lama semakin tinggi. Kebijakan ini diarahkan untuk mengendalikan jumlah pemarkir dipusat kota/pusat kegiatan dan mendorong penggunaan angkutan umum.

2. Kebijakan pembatasan ruang parkir, terutama didaerah pusat kota ataupun pusat kegiatan. Kebijakan ini biasanya dilakukan pada parkir dipinggir jalan yang tujuan utamanya untuk melancarkan arus lalu lintas, serta pembatasan ruang parkir di luar jalan yang dilakukan melalui IMB/Ijin Mendirikan Bangunan.

3. Kebijakan penegakan hukum yang tegas terhadap pelanggar ketentuan dilarang parkir dan dilarang berhenti serta pemarkir di luar tempat yang ditentukan untuk itu. Bentuk penegakan hukum dapat dilakukan melalui penilangan ataupun dengan gembok roda seperti yang dilakukan di Palembang.

\section{Keuntungan menggunakan strategi kebijakan parkir}

1. Untuk mengendalikan jumlah kendaraan yang masuk ke suatu kawasan.

2. Meningkatkan pendapatan asli daerah yang dikumpulkan melalui retribusi parkir.

3. Meningkatkan fungsi jalan sehingga sesuai dengan peranannya.

4. Meningkatkan kelancaran dan keselamatan lalu lintas.

5. Mendukung tindakan pembatasan lalu lintas lainnya

\section{Analisis sensitivitas dan linear regression}

Analisis sensitivitas merupakan analisis yang dilakukan pada solusi optimal suatu persolan program linear karna adanya perubahan parameter untuk melihat berapa besar perubahan dapat ditolerir sebelum solusi optimal mulai kehilangan optimalitasnya. Program linear merupakan suatu metode penyelesaian untuk memperoleh solusi optimal (maksimum/minimum) dari suatu persoalan. Salah satu tipe khusus dari persoalan program linear adalah persoalan transportasi. (Irawan, 2015)

Regresi linier adalah metode statistika yang digunakan untuk membentuk model hubungan antara variabel terikat (dependen; respon; Y) dengan satu atau lebih variabel bebas (independen, prediktor, X). Apabila banyaknya variabel bebas hanya ada satu, disebut sebagai regresi linier sederhana, sedangkan apabila terdapat lebih dari 1 variabel bebas, disebut sebagai regresi linier berganda. Analisis regresi setidak-tidaknya memiliki 3 kegunaan, yaitu untuk tujuan deskripsi dari fenomena data atau kasus yang sedang diteliti, untuk tujuan kontrol, serta untuk tujuan prediksi. Namun yang perlu diingat, prediksi di dalam konsep regresi hanya boleh dilakukan di dalam rentang data 
dari variabel-variabel bebas yang digunakan untuk membentuk model regresi tersebut, bentuk persamaan regresi linear sebagai berikut :

$$
\begin{aligned}
& b=\frac{(\mathrm{n} \cdot \Sigma \mathrm{xy})-(\Sigma \mathrm{x} \cdot \Sigma \mathrm{y})}{\left(\mathrm{n} \cdot \Sigma \mathrm{x}^{2}\right)-(\Sigma \mathrm{x} \cdot \Sigma \mathrm{x})} \\
& \mathrm{a}=\frac{\Sigma \mathrm{y}}{n}-\frac{\mathrm{b} \cdot \Sigma \mathrm{x}}{n} \\
& \mathrm{Y}=\mathrm{a}+\mathrm{b} \cdot \mathrm{X}
\end{aligned}
$$

dengan $\mathrm{Y}=$ variabel hasil prediksi, $\mathrm{a}=$ konstanta kurva linear, $\mathrm{b}=$ koefisiensi parameter laju, $\mathrm{X}=$ pertumbuhan beban variabel dan $n=$ jumlah data.

\section{METODOLOGI PENELITIAN}

Diperlukan metodologi penelitian yang runtut agar pelaksanaan penelitian efektif dan efisien. Sehingga setiap tahap kegiatan yang dilakukan dapat lebih terarah untuk mencapai tujuan dan hasil yang diharapkan. Langkah penelitian sebagai berikut :

Tahap I : Penetapan Tujuan, Metode Pengumpulan dan Analisis

Tahap II : Identifikasi Masalah

Tahap III : $\quad$ Penentuan Ruang Lingkup Penelitian

Tahap IV : $\quad$ Pembuatan Fomulir Survey

Tahap V : Pengumpulan Data

Tahap VI : Kompilasi Data

Tahap VII : $\quad$ Analisa Data

Tahap VIII : $\quad$ Kesimpulan dan Saran

\section{Metode pengumpulan data}

Pada penelitian ini menggunakan data - data yang diperoleh dari kuesioner responden yang disebar kepada pengguna kendaraan pribadi dan kendaraan umum di Jalan Raya Serpong Tangerang. Data responden yang diperoleh sebanyak 107 orang dari target 100 orang. Data responden didapatkan dengan penyebaran kuesioner secara langsung kepada responden yang beraktivitas dan melalui jalan tersebut yang menggunakan kendaraan pribadi dan kendaraan umum.

Data diambil dengan menggunakan kuesioner secara langsung sebanyak 107 responden. Analisis ini dimulai dengan memberikan gambaran umum mengenai data responden menggunakan Microsoft Excel untuk membuat chart dan juga menganalisis model sensitivitas untuk menentukan hasil dari kuesioner yang telah disebarkan. Data yang didapat berdasarkan hasil kuesioner dapat dilihat pada gambar berikut :

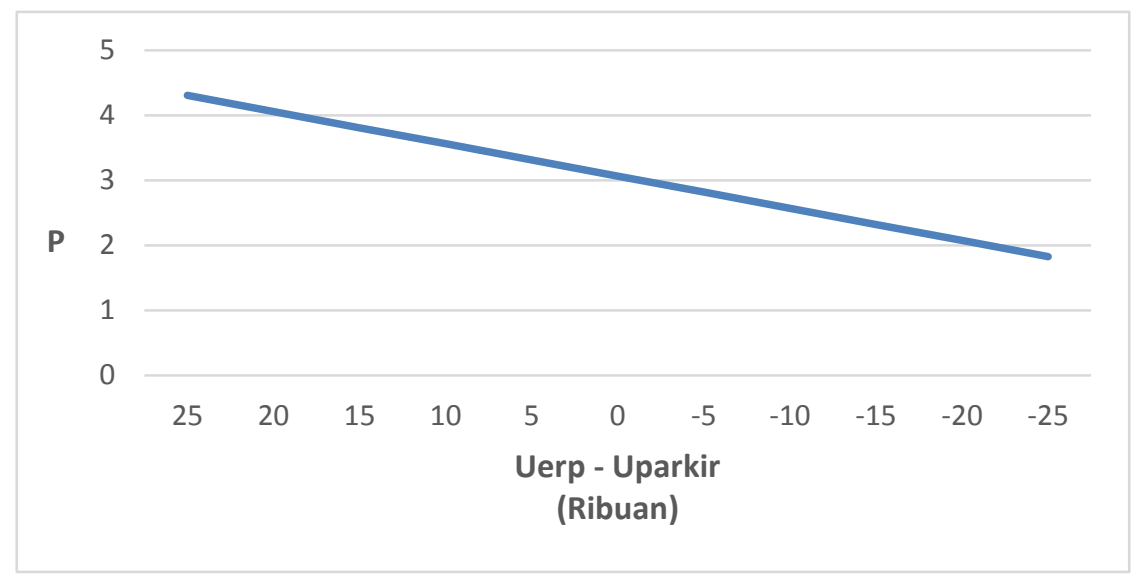

Gambar 1. Hubungan Selisih Utilitas ERP dan Parkir Terhadap Pilihan Parkir 


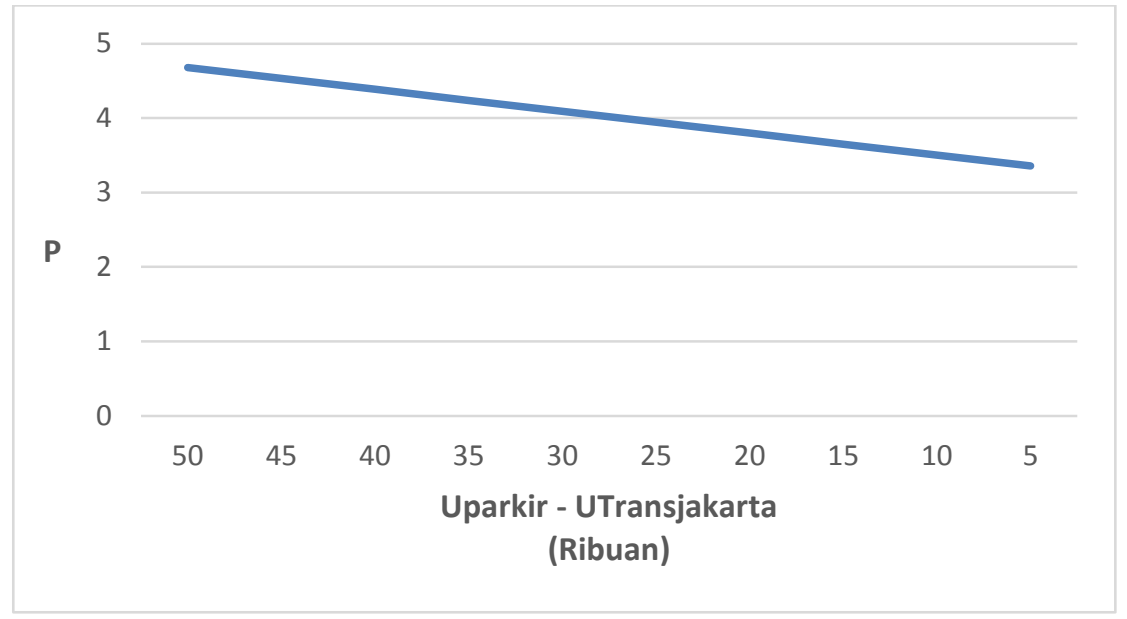

Gambar 2. Hubungan Selisih Utilitas Parkir dan Transjakarta Terhadap Pilihan Transjakarta Pada Pendapatan Kurang dari Rp 6.000.000

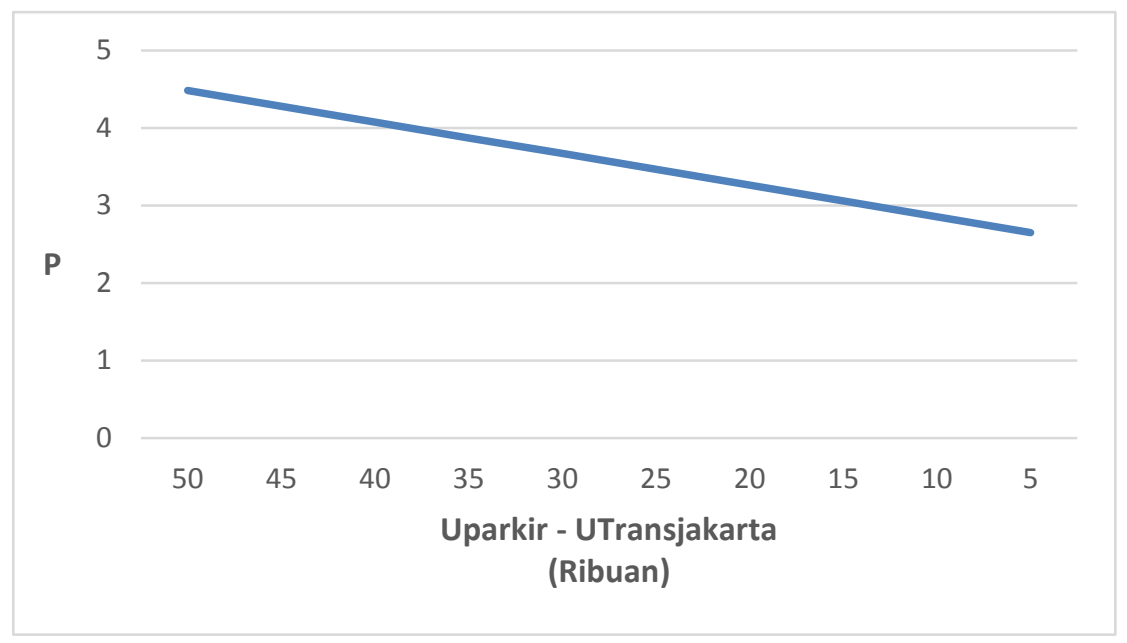

Gambar 3. Hubungan Selisih Utilitas Parkir dan Transjakarta Terhadap Pilihan Transjakarta Pada Pendapatan Lebih dari Rp 6.000.000

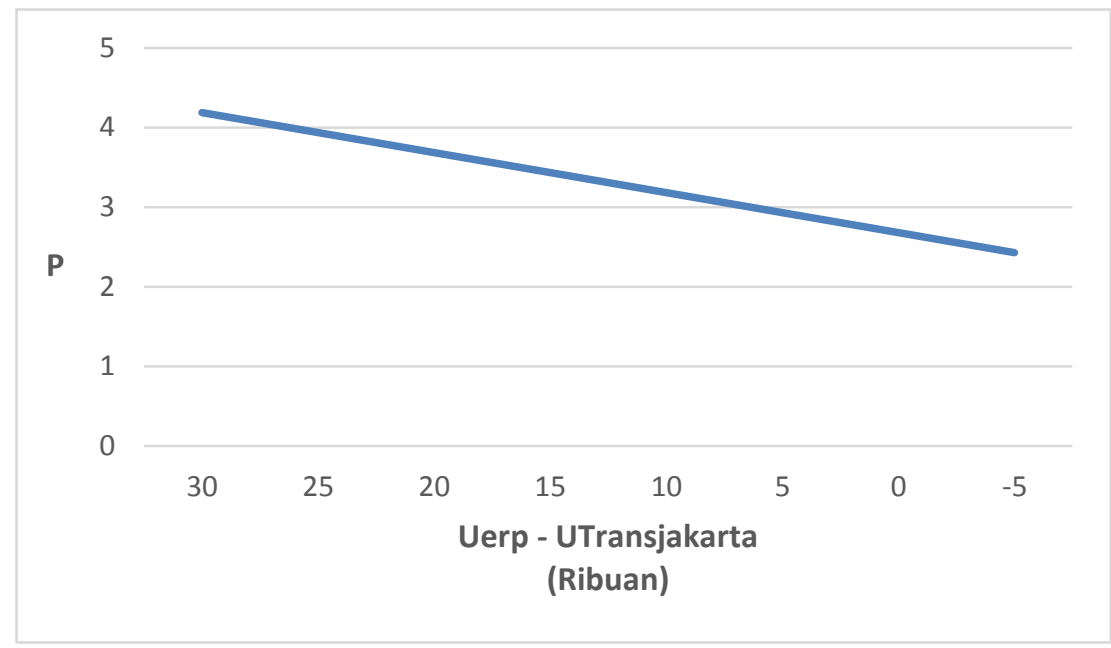

Gambar 4. Hubungan Selisih Utilitas ERP dan Transjakarta Terhadap Pilihan Transjakarta Pada Pendapatan Kurang dari $\operatorname{Rp} 6.000 .000$ 


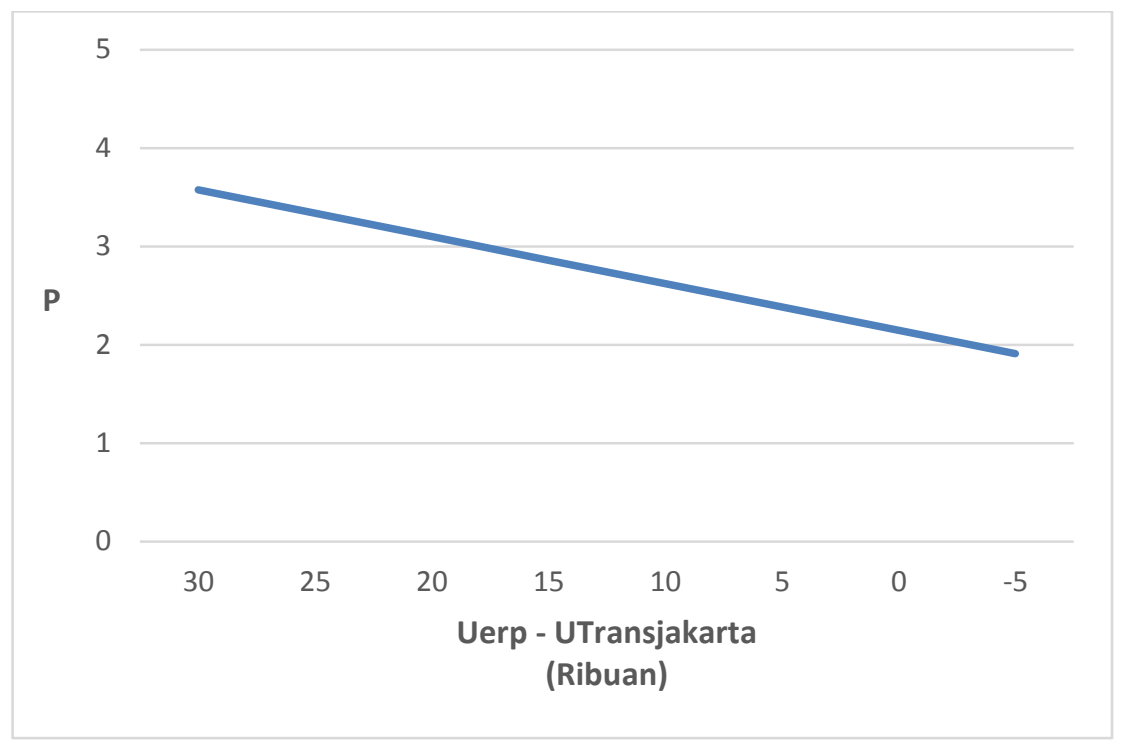

Gambar 5. Hubungan Selisih Utilitas ERP dan Transjakarta Terhadap Pilihan Transjakarta Pada Pendapatan Lebih dari Rp 6.000.000

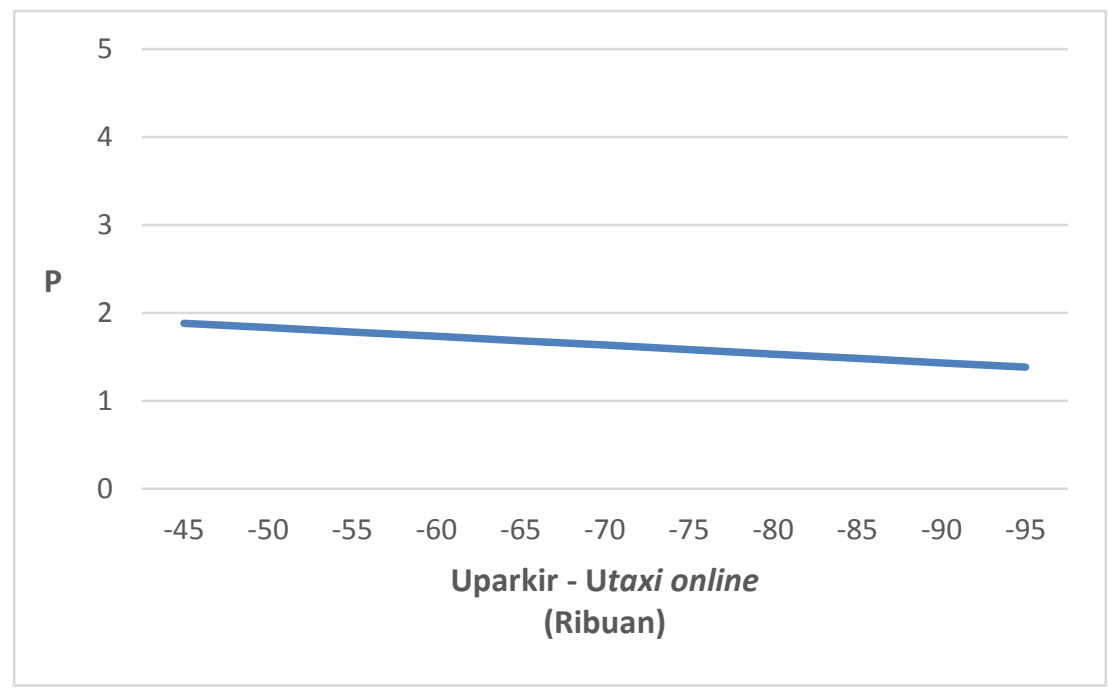

Gambar 6. Hubungan Selisih Utilitas Parkir dan Taxi Online Terhadap Pilihan Taxi Online

\section{Analisis sensitivitas model pilihan parkir terhadap utilitas ERP dan parkir}

Pada tabel ini dapat dilihat sensitivitas pilihan parkir terhadap utilitas ERP dan parkir untuk model total 107 responden. Total tarif skenario ERP pergi dan pulang sebesar Rp 50.000 dan data skenario parkir berbeda - beda 1 jam pertamanya dan 1 jam berikutnya dengan asumsi parkir 10 jam. Hasil analisis sensitivitas model ERP dan parkir dapat dilihat pada tabel 1 dibawah ini.

Hasil analisis sensitivitas didapatkan perbedaan rata - rata pilihan responden sebesar 0.248 dengan selisih setiap harga Rp 5.000. Sensitivitas model ini sebesar 4,96\%. Dari tabel 1 juga dapat disimpulkan bahwa semakin kecil biaya parkir maka responden lebih memilih parkir, dan semakin besar biaya parkir maka responden lebih memilih ERP. Hal ini dapat dilihat penurunan sensitivitas pada selisih pilihan responden ERP dengan parkir. 
Tabel 1. Analisis Sensitivitas Model Utilitas ERP dan Parkir Terhadap Pilihan Parkir

\begin{tabular}{cc}
\hline Uerp - Uparkir (Rp) & Pilihan Responden \\
\hline 25.000 & 4,3049 \\
\hline 20.000 & 4,0569 \\
\hline 15.000 & 3,8089 \\
\hline 10.000 & 3,5609 \\
\hline 5.000 & 3,3129 \\
\hline 0 & 3,0649 \\
\hline-5.000 & 2,8169 \\
\hline-10.000 & 2,5689 \\
\hline-15.000 & 2,3209 \\
\hline-20.000 & 2,0729 \\
\hline-25.000 & 1,8249 \\
\hline
\end{tabular}

\section{Analisis sensitivitas model pilihan Transjakarta terhadap utilitas parkir dan Transjakarta}

Pada tabel ini dapat dilihat perbandingan sensitivitas model pilihan Transjakarta terhadap utilitas parkir dan Transjakarta untuk model pendapatan kurang dari 6 juta dan model pendapatan lebih dari 6 juta. Kinerja dari setiap pertanyaan yang terdapat dalam kuesioner dari setiap poin 1 (Pilih Kendaraan Pribadi), 2 (Mungkin Pilih Kendaraan Pribadi), 3 (Ragu - Ragu), 4 (Mungkin Pilih Kendaraan Umum), dan 5 (Pilih Kendaraan Umum). Perbandingan tersebut dapat dilihat pada tabel 2 dibawah ini.

Tabel 2. Analisis Sensitivitas Model Pilihan Transjakarta Terhadap Utilitas Parkir dan Transjakarta

\begin{tabular}{ccc}
\hline Uparkir - UTransjakarta & \multicolumn{2}{c}{ Pilihan Responden } \\
\cline { 2 - 3 }$(\mathbf{R p})$ & 4,6767 & Pendapatan > Rp 6 Juta \\
\hline 50.000 & 4,5299 & 4,4820 \\
\hline 45.000 & 4,3832 & 4,2786 \\
\hline 40.000 & 4,2364 & 3,0752 \\
\hline 35.000 & 4,0896 & 3,8717 \\
\hline 30.000 & 3,9429 & 3,6683 \\
\hline 25.000 & 3,7961 & 3,4648 \\
\hline 20.000 & 3,6493 & 3,0579 \\
\hline 15.000 & 3,5026 & 2,8545 \\
\hline 10.000 & 3,3558 & 2,6510 \\
\hline 5.000 & & \\
\hline
\end{tabular}

Pada tabel 2 diatas didapatkan hasil analisis sensitivitas model pilihan parkir terhadap Transjakarta untuk responden dengan pendapatan kurang dari Rp 6.000.000 dan pendapatan lebih dari Rp 6.000.000. Untuk analisis sensitivitas model pilihan parkir terhadap Transjakarta, data skenario parkir dengan asumsi 10 jam dinaikkan tarif parkirnya sebesar Rp 2.000 per jamnya untuk setiap pertanyaan dan dengan rata - rata pengeluaran responden untuk angkutan umum (Transjakarta) sebesar Rp 40.000. 
Sensitivitas yang didapat dari tabel pendapatan kurang dari Rp 6.000 .000 sebesar 2,936 \% dan untuk pendapatan lebih dari Rp 6.000.000 sebesar 4,07 \%. Secara umum, pendapatan lebih besar memiliki nilai sensitivitas lebih kecil dibandingkan dengan pendapatan yang lebih kecil. Dari tabel diatas dapat dilihat bahwa pendapatan responden yang kurang dari Rp 6.000.000 cenderung lebih memilih kendaraan umum dibandingkan dengan pendapatan responden yang lebih dari Rp 6.000.000. Dari tabel 2 dengan selisih setiap harga Rp 5.000 dapat simpulkan bahwa semakin tinggi tarif parkir maka responden lebih memilih parkir dibandingkan untuk memilih menggunakan kendaran pribadi.

\section{Analisis sensitivitas model pilihan Transjakarta terhadap utilitas ERP dan Transjakarta}

Pada tabel ini dapat dilihat perbandingan sensitivitas model pilihan Transjakarta terhadap utilitas ERP dan Transjakarta untuk model pendapatan kurang dari 6 juta dan model pendapatan lebih dari 6 juta. Kinerja dari setiap pertanyaan yang terdapat dalam kuesioner dari setiap poin 1 (Pilih Kendaraan Pribadi), 2 (Mungkin Pilih Kendaraan Pribadi), 3 (Ragu - Ragu), 4 (Mungkin Pilih Kendaraan Umum), dan 5 (Pilih Kendaraan Umum). Perbandingan tersebut dapat dilihat pada tabel 3 dibawah ini.

Tabel 3. Analisis Sensitivitas Model Pilihan Transjakarta Terhadap Utilitas ERP dan Transjakarta

\begin{tabular}{ccc}
\hline Uerp - UTransjakarta & \multicolumn{2}{c}{ Pilihan Responden } \\
\cline { 2 - 3 }$(\mathbf{R p})$ & Pendapatan < Rp 6 Juta & Pendapatan > Rp 6 Juta \\
\hline 30.000 & 4,1888 & 3,5749 \\
\hline 25.000 & 3,9373 & 3,3369 \\
\hline 20.000 & 3,6858 & 3,0989 \\
\hline 15.000 & 3,4343 & 2,8609 \\
\hline 10.000 & 3,1828 & 2,6229 \\
\hline 5.000 & 2,9313 & 2,3849 \\
\hline 0 & 2,6798 & 2,1469 \\
\hline-5.000 & 2,4283 & 1,9089 \\
\hline
\end{tabular}

Pada tabel 3 diatas didapatkan hasil analisis sensitivitas model pilihan Transjakarta terhadap utilitas ERP dan Transjakarta untuk responden dengan pendapatan kurang dari Rp 6.000.000 dan pendapatan lebih dari Rp 6.000.000. Untuk analisis sensitivitas model pilihan Transjakarta terhadap utilitas ERP dan Transjakarta sebesar 5,03\% untuk pendapatan kurang dari Rp 6.000.000 dan untuk pendapatan lebih dari Rp 6.000.000 sebesar 4,76\%, data skenario ERP dinaikkan tarif ERP sebesar Rp 20.000 untuk setiap pertanyaan dan dengan rata - rata pengeluaran responden untuk taxi online sebesar Rp 120.000.

Tabel 3 dengan perbedaan selisih harga Rp 5.000 menunjukkan perbedaan yang cukup signifikan antara responden dengan pendapatan kurang dari Rp 6.000 .000 yang cenderung ragu - ragu dan memilih kendaraan umum dengan responden dengan pendapatan lebih dari Rp 6.000.000 yang ragu - ragu dan memilih kendaraan pribadi, hal ini dikarenakan responden dengan pendapatan lebih dari Rp 6.000.000 dapat menghemat waktu lebih banyak jika memilih menggunakan pilihan ERP.

\section{Analisis sensitivitas model pilihan taxi online terhadap utilitas parkir dan Taxi Online}

Pada tabel ini dapat dilihat model sensitivitas pilihan taxi online terhadap utilitas parkir dan taxi online di Jalan Raya Serpong yang terdiri dari kinerja dari setiap pertanyaan yang terdapat dalam kuesioner dari setiap poin 1 (Pilih Kendaraan Pribadi), 2 (Mungkin Pilih Kendaraan Pribadi), 3 (Ragu - Ragu), 4 (Mungkin Pilih Kendaraan Umum), dan 5 (Pilih Kendaraan Umum) pada tabel 4 di bawah ini.

Pada analisis sensitivitas model pilihan taxi online terhadap utilitas parkir dan taxi online di Jalan Raya Serpong, rata - rata pengeluaran responden untuk angkutan umum (Taxi Online) sebesar Rp 120.000. Sensitivitas model pilihan taxi online terhadap utilitas parkir dan taxi online didapat sebesar $1 \%$. Tabel 4 dengan selisih setiap harga Rp 5.000 menunjukkan bahwa responden lebih memilih menggunakan kendaraan pribadi dengan asumsi parkir 10 
jam dibandingkan menggunakan kendaraan umum taxi online dikarenakan perbedaan selisih tarif antara tarif parkir dengan tarif taxi online yang cukup besar.

Tabel 4. Analisis Sensitivitas Model Pilihan Taxi Online Terhadap Utilitas Parkir dan Taxi Online

\begin{tabular}{cc}
\hline Uparkir - Utaxi online (Rp) & Pilihan Responden \\
\hline-45.000 & 1,8823 \\
\hline-50.000 & 1,8323 \\
\hline-55.000 & 1,7823 \\
\hline-60.000 & 1,7323 \\
\hline-65.000 & 1,6823 \\
\hline-70.000 & 1,6323 \\
\hline-75.000 & 1,5823 \\
\hline-80.000 & 1,5323 \\
\hline-85.000 & 1,4823 \\
\hline-90.000 & 1,4323 \\
\hline-95.000 & 1,3823 \\
\hline
\end{tabular}

\section{KESIMPULAN}

1. Dari 107 responden, didapatkan grafik analisis sensitivitas dari hasil model sensitivitas antara sistem Electronic Road Pricing (ERP) dengan kebijakan parkir yang menunjukkan bahwa responden akan lebih memilih tarif yang lebih murah untuk keperluan tertentu apabila dibandingkan tarif ERP dengan tarif kebijakan parkir.

2. Dari hasil model sensitivitas kebijakan parkir terhadap kendaraan umum Transjakarta didapatkan grafik analisis sensitivitas yang menunjukkan bahwa semakin rendah pendapatan maka sensitivitas responden untuk memilih kendaraan umum Transjakarta lebih tinggi. Padahal pada umumnya, pendapatan semakin besar pendapatan maka sensitivitas responden lebih kecil.

3. Perbandingan grafik model sensitivitas ERP terhadap kendaraan umum Transjakarta menunjukkan bahwa responden masih ragu - ragu untuk menggunakan kendaraan pribadi dan mungkin memilih kendaraan umum Transjakarta untuk transportasi sehari - hari karena selisih tarif yang tinggi.

4. Hasil grafik model sensitivitas kebijakan parkir terhadap taxi online menunjukkan responden lebih memilih menggunakan kendaraan pribadi dengan sistem kebijakan parkir dibandingkan menggunakan taxi online dikarenakan perbedaan selisih tarif yang tinggi.

5. Berdasarkan perbandingan sistem ERP dan kebijakan parkir dengan transportasi umum Transjakarta dan taxi online, penulis dapat menark kesimpulan bahwa masyarakat atau responden memilih berdasarkan tarif. Semakin tinggi tarif ERP atau kebijakan parkir yang ditetapkan maka semakin besar kemungkinan pengguna jalan beralih menggunakan kendaraan umum.

\section{SARAN}

1. Perlunya dilakukan sosialiasi oleh pemerintah mengenai sistem kebijakan ERP dan kebijakan parkir kepada masyarakat agar dapat tersampaikan dengan baik dan masyarakat mengetahui dampak positif dari sistem kebijakan tersebut.

2. Apabila sistem kebijakan ERP atau kebijakan parkir diterapkan, pemerintah harus mempersiapkan peraturan peraturan yang terkait untuk mendukung penerapan sistem ERP atau kebijakan parkir.

3. Dilakukannya penelitian lebih lanjut mengenai sistem ERP atau kebijakan parkir di Jalan Raya Serpong untuk mengumpulkan memperdalam informasi sebelum diterapkan sistem tersebut.

4. Apabila sistem ERP atau kebijakan parkir diterapkan, adanya juga pengawasan yang tegas dan efektif untuk menegakkan peraturan yang sudah dibuat. 


\section{DAFTAR PUSTAKA}

Abubakar, I. (2011). Parkir, Pengantar Perencanaan dan Penyelenggaraan Fasilitas Parkir.

Bathia, D. P. (2018). Pengendalian Penggunaan Mobil Pribadi Dengan Strategi Parkir dan ERP di Jalan Rasuna Said DKI Jakarta. Skripsi. Tidak diterbitkan. Fakultas Teknik Universitas Tarumanagara. Jakarta

Daniel, J. I., \& Bekka, K. (2000). The Environmental Impact of Highway Congestion Pricing. Journal of Economics. Jakarta

Dinas Perhubungan Tangerang. (2011). Electronic Road Pricing. Dinas Perhubungan Provinsi Tangerang

Paparan PCI, PCKK, dan Sumitimo Corporation. (2008). "The Study on Jakarta Road Pricing in the Republic of Indonesia." .Jakarta

Petrick, D. S. (2018). Pengendalian Mobil Pribadi Dengan Strategi Parkir dan ERP di Jalan Sudirman - Thamrin di DKI Jakarta. Skripsi. Tidak diterbitkan. Fakultas Teknik Universitas Tarumanagara. Jakarta

Pratama, O. (2012). Analisis Rencana Penerapan Electronic Road Pricing (ERP) pada Sektor Transportasi terhadap Kota Jakarta Menggunakan Pendekatan Sistem Dinamis. Universitas Indonesia, DKI Jakarta

Susantono, B. Electronic Road Pricing (ERP) Salah Satu Solusi Masalah Kemacetan di Kota Jakarta, Buletin Tata Ruang, September - Oktober 2008 